\title{
Cambio histórico, sociedad secular e Iglesia. Interpretaciones del mundo católico ante un contexto de transformación. Chile, 1960-1964
}

\author{
Marcos Fernández \\ DEPARTAMENTO DE HISTORIA \\ UNIVERSIDAD ALBERTO HURTADO \\ mfernand@uahurtado.cl
}

Resumen: El presente artículo busca reconstituir e interpretar históricamente la percepción del cambio histórico al interior del pensamiento católico chileno durante la primera mitad de la década de 1960. Apoyados en fuentes destinadas al debate público así como en investigaciones sociológicas elaboradas en el periodo, se plantean las siguientes conclusiones: entre los factores del cambio histórico se anotaban el proceso de secularización y la articulación de una sociedad plural en Chile; la actitud frente a estos cambios no fue homogénea, conviviendo al interior de la opinión católica posturas que apoyaban los cambios y otras que los percibían con temor; como forma coherente de asumir los desafíos del cambio histórico, se formularon al interior de la Iglesia Católica chilena juicios y acciones orientadas a fortalecer su presencia en la opinión pública, así como a transformar sus propias estructuras y procedimientos.

Palabras clave: Iglesia Católica, Historia de Chile, Cambio Histórico, Secularización, Siglo XX.

Abstract: This article aims to make an historical interpretation about the perception of historical change inside the Catholic thought in Chile during the first half of the 1960s. Supported in historical sources for the public discussion -as well as sociological research published in the period- it is possible to formulate the following conclusions: secularization and the formation of a plural society were taken as factors of historical change; in front of these transformations, Catholic opinion maintained an attitude of rejection and support; however, the Catholic Church decided to strengthen its presence in the public field, and transform their own structures and procedures.

Keywords: Catholic Church; Chilean History, Historical Change, Secularization; XX Century. 


\section{INTRODUCCIÓN}

A inicios de la década de 1950, el obispo de Talca Manuel Larraín E. (1900-1966), con particular claridad definió el contexto de secularización y cambio histórico en el que transitaría la Iglesia Católica en los años venideros, marcados por el hecho de que "el ritmo de la historia se acelera, cambios rápidos e insospechados antes conmueven las instituciones y las costumbres", provocando con ello que "las divisiones sociales y políticas se hacen más agudas y violentas". Ante dicha situación inexorable, la convicción del religioso apuntó hacia la máxima de que "lo espiritual debe animar lo temporal", permaneciendo cada esfera como ámbito propio, pero no en un sentido negativo o de aislamiento católico, sino bajo la consigna de que "la Iglesia no tiene por fin que este

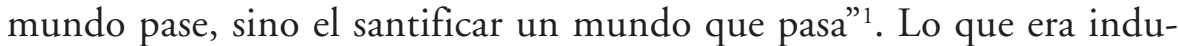
dable, sin embargo, era que ese mundo que pasaba estaba cambiando, y sus transformaciones se percibían en multitud de esferas y situaciones.

No es nuestra intención en estas páginas abordar el complejo campo de la opinión y debate político eclesial en el periodo, sino que analizar con algo de detención la comprensión que al interior de algunos de los agentes del pensamiento católico chileno se realizaba en torno a un proceso si se quiere anterior y aún más significativo que los dimes y diretes de la arena política: el cambio histórico. El sentido de esta precisión estriba en el hecho de que las condiciones de este cambio, al ser reconocidas como evidentes, de alguna forma forzaron a la intervención política por parte de la institución eclesiástica, usando para ello los distintos dispositivos previstos para ello: la Acción Católica, la prédica, las instituciones de educación y formación, los medios de prensa y de comunicación destinados a la esfera pública y al mundo intra-eclesial. Bien sabemos que la misma Iglesia Católica fue un actor imprescindible en la constitución y ampliación de esta esfera pública². Lo que la condición del cambio histórico hacía era poner en tensión, desde distintos flancos, el uso y eficacia de los mecanismos de intervención temporal que la misma institución había fraguado.

1 M. Larraín, "Trascendencia de la Iglesia" (1952), en Escritos Completos, Vol. I (Ediciones Paulinas, Santiago de Chile, 1976) 32-35

2 S. Serrano, ¿Qué hacer con Dios en la República? Política y secularización en Chile (1845-1885), (FCE, Santiago de Chile, 2008) 23. S. Serrano, "Espacio público y espacio religioso en Chile republicano", en Teología y Vida 44/2-3 (2003) 348. 
Pues bien, todo lo anterior se enmarcaba en un proceso complementario, de algún modo paralelo: el ciclo de secularización que -nuevamente, de acuerdo al común de nuestras fuentes- se desplegaba incansable en la sociedad chilena desde fines del siglo XIX. Si bien, nuevamente, no es este el lugar para dar una discusión detallada a este respecto, es imprescindible reseñar al menos las distintas variables que el análisis histórico-conceptual ha elaborado al respecto en las últimas décadas, en tanto sus líneas de debate pueden ser ilustrativas para dimensionar los alcances del tipo de debate que pasaremos a reconstituir e interpretar. Así, y a partir en lo fundamental de la obra de J. Habermas, la secularización ha sido comprendida como una de las dinámicas intrínsecas de la modernización, estableciéndose por ello la articulación de una esfera pública en la cual los contenidos del diálogo social son racionalmente formulados, gracias a su cualidad de neutralidad religiosa. Así, los agentes de opinión que participan en la discusión pública lo hacen dejando a un lado sus creencias y adscribiendo a formulaciones por todos reconocidas como válidas. Ello implicaría, más temprano que tarde, el repliegue del fenómeno religioso a la intimidad de los sujetos, y producto de ello, su virtual desaparición.

A partir del análisis histórico más detallado, un conjunto de autores -especialmente Charles Taylor y José Casanova- han anotado que el proceso antes descrito quizás podría servir para reflejar la situación histórica específica de algunas sociedades europeas a partir de fines del siglo XVIII, pero que de ninguna forma es aplicable al conjunto de la humanidad, ni tampoco a todas aquellas sociedades que han experimentado ciclos de modernización, siendo ejemplos muy relevantes de ello los Estados Unidos y América Latina. En ese sentido, lo que se ha observado en estos casos es que la religión no actúa de forma institucionalizada en el espacio público - con intención hegemónica-, sino que es reconocida como un insumo legítimo de orientación en la vida política, destacándose en tal sentido tanto los contenidos de verdad ética que las creencias religiosas comúnmente contienen y que serían posibles de proponer a creyentes y no creyentes en la esfera pública, como el rechazo a la lógica fundamentalista o ultramontana que suponía -y en algunos lugares aún supone- el objetivo de la imposición de una creencia única en detrimento de todas las demás. En el caso que pasamos a analizar, la secularización fue comprendida por el pensamiento católico chileno como un estado de cosas en gran medida inevitable, como una condición que fue aso- 
ciada a la articulación de una sociedad plural. Esa definición supuso dos componentes centrales: en primer lugar, las estrategias para comprender un cambio histórico secularizante, diverso, inevitable; en segundo, las transformaciones que este proceso debía promover en la misma Iglesia Católica chilena. Ambos temas se desarrollan a continuación.

I. EL PROBLEMA DEL SECULARISMO EN EL PENSAMIENTO CATÓLICO CHILENO EN LA PRIMERA MITAD DE LA DÉCADA DE 1960

La coincidencia de transformaciones estructurales aceleradas, secularización de la cultura y aparición de nuevos agentes de opinión política fue tempranamente advertida, en distintos niveles, por representantes de la Iglesia Católica chilena, quedando evidencia de ello en distintos planos de la reflexión y la opinión del campo católico. Así, por ejemplo, a las admoniciones que antes citábamos de Manuel Larraín se puede adicionar el informe que el sacerdote Rafael Larraín E. (1915-1975) redactó para dar cuenta de las tareas del Instituto de Educación Rural, en el cual anotaba el influjo de las ideas citadinas y secularizantes sobre la población campesina, advirtiendo en ello tanto un cambio de "mentalidad", como la progresión del comunismo y la necesidad de reforzar la dignidad campesina "que desea más independencia y libertad"3.

Pero no eran solo los campesinos o los obreros sujetos a la influencia moderna, sino que era "la gran mayoría de nuestros católicos, de la clase social que sean" quienes estaban influidos por lo que -en la presentación del primer número de Teología y Vida, la revista de la Facultad de Teología de la Universidad Católica de Chile- los teólogos ahí convocados denominaron "secularismo: el buscar nuestro cielo aquí en la tierra; el valorizar nuestras acciones por lo útil ("utilitarismo"); el juzgar todo intento, aún en lo espiritual, por los resultados inmediatos que produzca ("pragmatismo")". A su juicio, la reunión de teología y vida era una forma de combatirlo, y para hacerlo no bastaba "que la Fe se esté pensando en Roma o en París o en Múnich. Es preciso que la pensemos en

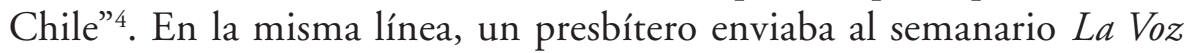

3 R. Larraín E., "El IER: una respuesta al problema rural", en Mensaje 93 (octubre 1960) 426-428. El autor agregaba: "no hay joven o niña campesino que no esté decidido a vestir como los personajes de las películas y de las novelas y a gozar de todas las comodidades de las que ha oído hablar".

4 Teología y Vida 1/1 (primer trimestre 1960), presentación. 
- propiedad del Arzobispado de Santiago- su opinión de que "el mundo actual está orgulloso de sus progresos. Esto ha creado una generación suficiente" en la que "se perfila una actitud en que a cada instante se atisba el orgullo. Este estilo de vida hace difícil a una mentalidad contemporánea el escándalo de un Dios nacido en la pobreza y muerto en la humillación"s. Es decir, el secularismo no se relacionaba con un cuerpo de doctrinas políticas predefinidas o con un programa posible de intencionar, sino que con una serie de actitudes dirigidas a medir la acción histórica desde criterios exclusivamente pragmáticos, incluso la acción histórica por definición no secular, es decir, la religiosa.

En este sentido, es relevante el hecho de que desde temprano en la opinión católica se distinguieron ciertos factores intra-eclesiásticos que favorecerían este tipo de conductas secularizadas, responsabilizando así no solo al "mundo" del proceso, sino también diagnosticando qué tipo de prácticas de la misma Iglesia Católica reforzaban esta situación. Así, a juicio del sacerdote holandés Ireneo Rosier -que en 1960 se desempeñaba como profesor de Psicología Social en la Escuela de Sociología de la Universidad Católica de Chile- este tipo de factores se resumían en el excesivo intelectualismo del clero; su persistente paternalismo sobre los laicos, que impedía la madurez religiosa de estos; la lógica del culto católico, que exigía de los fieles conocimientos que no eran comunes en la generalidad de la población; "la comunión no vivida", es decir, la inexistencia de agrupaciones pequeñas de laicos que experimentasen dinámicamente su fe y la falta de relación "dialéctica" entre el sacerdote y los feligreses ${ }^{6}$. Para otro comentarista, sin embargo, era justamente la escasa profundidad y claridad de la educación religiosa y la catequesis entregada en la educación católica lo que producía que no fuera "raro que al entrar a una Universidad laica haya muchos que pierdan la fe"

Fuera de lo anterior, el proceso de secularización era algo que se inscribía en la dinámica del mundo contemporáneo, en las lógicas que animaban a sus agentes y que -en este caso para el jesuita José Aldunate (1917-)- derivaban en una suerte de desencantamiento de la experiencia y la acción, al ser privadas de cualquier alcance ideal, o en sus palabras,

5 G. Ascuí, "Humildad Cristiana", en La Voz (26 de junio 1960) 3.

6 I. Rosier Reseña al libro "Ovejas sin pastor. Problemas del cristianismo actual”, en Teología y Vida 1/3 (tercer trimestre de 1960) 198.

7 "Cuatro problemas para un Continente", en $\operatorname{La}$ Voz (13 de marzo 1960) 10. 
"ideológico": la "desconfianza frente a las ideologías está llevando al hombre de posguerra a lanzarse en brazos de la técnica. El gran peligro de hoy es el de la tecnocracia. No pueden ser los técnicos los que gobiernan al mundo" ${ }^{8}$. De esa forma, el temor manifiesto -en el contexto preciso de la implementación de políticas destinadas a la reconstrucción del sur del país tras el devastador terremoto de mayo de 1960- era el predominio de la razón técnica, del instrumental y pragmático sello de la modernidad así en su vertiente liberal como en su operacionalización socialista. La nostalgia por la "ideología" era la nostalgia por una experiencia no alienada, por una realidad apartada del solo cumplimiento de las leyes de la materia. Ante el desierto de la cosificación, Aldunate se preguntaba "si no será preferible la misma lucha ideológica, con la consiguiente pobreza material si se quiere, en que el hombre sabe por qué vive y por qué muere" como alternativa "a ese enajenamiento de la vida humana, hecha robot, a esa muerte del hombre bajo el peso aplastante de la materia" Es decir, la secularización implicaba para el jesuita un vaciamiento de sentido para la acción terrena, apartada de la experiencia que, incluso planteada como "ideológica", suponía una veta de trascendentalidad.

Sin embargo, para otro observador, las condiciones de esta lucha ideológica serían potencialmente contraproducentes para el pensamiento católico -especialmente en América Latina-, en tanto este continente, transformado en tierra de misión, se caracterizaba por su "catolicismo notablemente débil para enfrentar el progreso moderno", por su carácter acendradamente místico y poco "encarnado"10. Como ejemplo de ello,

8 J. Aldunate, “Teología y Reconstrucción”, en Teología y Vida 1/4 (cuarto trimestre 1960) 230.

9 J. Aldunate, “Teología y Reconstrucción” 230. Pocas páginas más adelante, para uno de los redactores de la misma publicación esta "lucha ideológica" se daba en los siguientes términos: "Técnica, ciencia, entretención; sin metas, sin moral, sin sentido propiamente humano, sin sentido de Dios. La Iglesia se encuentra frente a una tarea gigantesca: domar y cristianizar una vez más la barbarie” Teología y Vida $1 / 4$ (cuarto trimestre 1960) 240. En un sentido muy similar, uno de los redactores habituales de $L a$ Voz manifestaba sus cuestionamientos a la glorificación que el comunismo hacía de sus éxitos científicos -al calificarse la proeza de Yuri Gagarin como "la hazaña humana más grande la historia"-, en tanto el mundo de la técnica y sus avances solo aportarían al hombre "poder sobre las cosas y enriquecimiento material”. La Voz (7 de mayo 1961) 19.

10 R. VeKemans, citado en "La Iglesia pierde terreno en América latina", en La Voz (24 de enero 1960) 12. 
uno de los más destacados promotores del giro social de la Iglesia Católica contemporánea, el dominico francés J. Lebret (1897-1966), advertía a los lectores de La Voza inicios de 1960 los factores que colaboraban en el distanciamiento de las clases obreras con respecto a la Iglesia Católica, en tanto las prácticas litúrgicas estaban marcadas por "manifestaciones infantiles", un lenguaje no debidamente "adaptado" y una predicación "anticuada". A su juicio, el sacerdote aparecía como "un hombre de otro mundo, atrasado y ridículo", que invitaba tan solo a "arrodillarse delante de estatuas amaneradas, en una iglesia fea, a oír cánticos de un sentimentalismo soso y a alinearse en directivas políticas de pocos alcances". Se preguntaba el sacerdote si todo ello no debía ser visto si no como "una alienación inadmisible"11.

Con respecto a otros sectores sociales, para algunos agentes del clero chileno era el laicismo como ideología la tendencia secularizante que debía atenderse con decisión. Así, a juicio del obispo de Temuco Bernardino Piñera (1915-) tres eran los grandes enemigos del catolicismo a inicios de la década de 1960: el laicismo, el protestantismo y el marxismo. Sobre el primero, a su juicio se había instalado fuertemente entre las clases medias y una porción de la elite, expresándose políticamente por medio del radicalismo y el liberalismo políticos y siendo irrigado tanto por la masonería como por "las influencias europeas y norteamericanas, en el orden científico-técnico, y en el orden de las costumbres". De acuerdo al religioso, los "feudos" del laicismo eran "la Administración Pública, la asistencia social, y sobre todo la educación fiscal. También el mundo de los negocios, y el mundo de las entretenciones". En el plano de lo estrictamente religioso, el laicismo poseía en su opinión un rostro antirreligioso -propio de la masonería-, y otro "amoral o inmoral" propio de las corrientes liberales, "impulsado por la influencia europea y norteamericana, y por los grandes intereses económicos relacionados con la prensa, el cine, el teatro, el diario, las entretenciones, y el mundo de los negocios". Al momento de evaluar la centralidad que debía reconocer la Iglesia en su enfrentamiento contra el laicismo, el Obispo se mostraba ambiguo, en tanto advertía que esta corriente secularizadora "ha hecho y sigue haciendo un mal inmenso", pero también observaba que "no es el único enemigo. Hay otros peores que él y frente a los cuales tendremos tal vez que pelear juntos", en solapada referencia al marxis-

11 J. Lebret, “Qué pasa con el obrero", en $\operatorname{La} \operatorname{Voz}(27$ de marzo 1960) 8. 
mo. Además, reconocía, el laicismo era "el viejo enemigo, el que conocemos ya hace muchos años, el que ya no nos asusta", en tanto había "perdido mucho de su virulencia primitiva, y sus posiciones nos parecen añejas y trasnochadas".

Finalmente, le resultaba importante recordar que a fin de cuentas el laicismo mantenía una "gran debilidad", en tanto en su oposición al catolicismo solo "destruye, pero no reemplaza", en términos de haberse demostrado incapaz - "desde Robespierre hasta Comte"- de superar "el ridículo" y "la ineficacia" en términos de articular una moral sostenible y alimentada por una "mística". Por ello, quienes se acercaran al laicismo, a la larga, "volverán al catolicismo - ¡cuántos han vuelto!- o seguirán en su ruta de extravío hacia la luz fascinante y engañosa del marxismo" ${ }^{2}$. Un par de años más tarde, el jesuita Juan Ochagavía (1928-) -desde el Centro Bellarmino- sumaba a estas amenazas una serie de "herejías de nuestro tiempo", que tematizaba como "la apología triunfante de la desesperación" y el "escepticismo de la verdad", alimentada la primera por el "existencialismo de posguerra" y el segundo por "el relativismo historicista, el culturalismo y el positivismo lógico"13.

De esa forma, el proceso de secularización -asociado explícitamente por nuestras fuentes a la modernización y al laicismo- era constatado, definido y en gran medida temido por los representantes del pensamiento católico que hasta aquí hemos citado, dando cuenta de los distintos planos en que su condición amenazante se prefiguraba: desde el campo de la política y la vida corriente de las personas, hasta el plano de la pérdida de sentido y horizonte de trascendencia que alcanzaba a representar. Hecho el diagnóstico y dimensionado el alcance de las tareas que suponían revertir estos efectos juzgados como negativos, la instalación de la secularización en el plano mayor del cambio histórico que caracterizaba a la sociedad chilena del periodo fue un reflejo inmediato de la reflexión católica, determinándose así una serie de condiciones para su accionar que lejos de apartar a la Iglesia chilena del mundo, operaron como incentivos para una "encarnación" mayor.

12 B. Piñera, "La Iglesia Chilena en medio de las corrientes ideológicas actuales", en Pastoral Popular 65 (septiembre-octubre 1961) 3-9.

13 J. Ochagavía, "La Iglesia en la realidad actual", en Teología y Vida 4/3 (tercer trimestre 1963) 179-187. 


\section{EL CAMBIO HISTÓRICO EN LA OPINIÓN CATÓLICA CHILENA}

Como contexto significante de todo lo anterior, los planos del cambio histórico se volvían pronunciados en el campo de la política y las relaciones sociales que definían al Chile de la segunda mitad del siglo XX. Con la década de 1960 llegaba la época de las reformas, y el país pasaba -a juicio del semanario del Arzobispado de Santiago- de ser en extremo conservador, a ser extremadamente reformista, desenvolviéndose la oferta de planes decenales de desarrollo, reformas agrarias, tributarias, educacionales, constitucionales y demás, "de todos los colores y sabores". Así, el reformista en Chile se enfrentaba ya no al problema de "clamar en el desierto", sino a la "dificultad de elegir entre tantas reformas y tantos reformismos que han brotado como hongos de la tierra o que deslumbran como una pirotecnia". Sin negar la necesidad de tales transformaciones, el vocero del Arzobispado advertía sin embargo que el ánimo reformista -descrito como una "estructura psicológica de nuestra política"- podía ser "el principio de una acción efectiva y puede ser también el principio de una peligrosa comedia colectiva", dado que "las reformas no son fáciles; muchas de ellas serán dolorosas y perturbadoras en la misma medida que sean efectivas. Y es muy fácil que, sin percibirlo, nos juguemos una mala pasada" ${ }^{14}$. Se trataba de poner así algo de cautela frente a los cambios, una nube de conservadurismo que con la tradicional desconfianza ante la política, recordaba el riesgo del cambio histórico, y haciendo uso de una trágica prognosis, visualizaba algunos de sus puntos de quiebre.

En la misma línea, pocos días más tarde uno de los redactores habituales del mismo semanario se preguntaba “¿Qué es el cambio?”, advirtiendo la persistencia de enfoques que lo vinculan al peligro y al desorden -porque "muchas veces lo ha sido"-, y su convicción de la necesidad de entender "el cambio histórico, político, social, no como un acontecimiento que llega y pasa. Es un proceso continuo que está sucediendo ahora, como ayer y como mañana". En su vorágine, el cambio "trae elementos desconocidos, que nadie puede prever. Por eso mismo, no se le puede controlar". Como receta para contener "el miedo, que solo consigue hacer más grave al peligro", José Gorbea -seudónimo del laico activo de largo compromiso público Javier Lagarrigue A. (1915-

$14 \quad$ La Voz (2 de julio 1961) 20. 
1987) - recomendaba la evangélica cita de que "bástale a cada día su afán", siendo en ese momento "las nuevas formas de la justicia, de la dignidad del hombre y de la fraternidad humana, largo tiempo reprimidas e ignoradas"15.

Así, la tonalidad de las transformaciones se asumía como justa, necesaria, loable. Junto a tales cualidades, el cambio histórico era -a juicio de un lector del mismo semanario- inevitable, y cargado desde un inicio con la amenaza de que "la nueva sociedad que está naciendo de las ruinas que nos legó el liberalismo individualista y materialista, sea una sociedad francamente atea" ${ }^{\prime 16}$. Similares preocupaciones animaban a los estudiantes universitarios católicos, quienes reunidos en la Parroquia Universitaria se preguntaban en 1962 en torno a las características del cambio social y el papel que en él debían jugar los cristianos. Invitado a responder tales preguntas, el agrónomo Jacques Conchol (1926-) reflexionaba -a partir de su experiencia- en torno a los factores participantes de las transformaciones que su juicio eran evidentes a escala continental: "la pérdida de fe en sí misma de la clase dirigente, el fracaso del sistema capitalista y la profunda difusión que han alcanzado las ideas de libertad, igualdad y justicia”. Es decir, para el futuro ministro de agricultura de Salvador Allende y uno de los más informados planificadores de la Reforma Agraria, las razones del cambio eran en su mayoría negativas, producto de la inconsistencia de las elites y la incapacidad del modelo capitalista para producir y distribuir riqueza de forma suficiente. Es decir, a una causa sociológica se sumaba otra estructural, que movilizadas por la impronta de un discurso progresista hacían inevitable el cambio histórico y forzaban a los jóvenes militantes católicos a ubicarse "a la cabeza de este cambio", dotados de una "actitud revolucionaria" ${ }^{17}$. ¿Era expresión de esta "actitud revolucionaria" la decisión del obispado de Talca de entregar 182 hectáreas de tierra agrícola a sus inquilinos -organizados en una cooperativa- en junio de 1962? Es probable que Chonchol así lo considerase en ese momento. Lo que aquí interesa es que al

\footnotetext{
15 “QQué es el cambio?”, en $\operatorname{La}$ Voz (9 de julio 1961) 20. Agradezco al periodista Abraham Santibáñez el haberme aportado el nombre que escribía bajo el seudónimo de José Gorbea, en el marco de la donación de la colección completa del semanario arzobispal a la Biblioteca de Humanidades de la Pontificia Universidad Católica de Chile a fines de julio de 2015.

16 "Gorbea no está solo", en La Voz (11 de marzo 1962) 2.

17 "Para Universitarios. Una parroquia revolucionaria”, en $\operatorname{La}$ Voz (6 de mayo 1962) 12.
} 
momento de definir lo que este gesto de la Iglesia Católica con el cambio social representaba, el obispo Manuel Larraín expresó a los campesinos que lo oían: "a través de esta experiencia yo veo surgir un nuevo día del campesinado chileno. Un Chile que avanza confiado en la nueva edad histórica que comienza"18. El cambio histórico ya estaba aquí.

En términos referidos puntualmente a la comprensión de este proceso de cambio histórico en relación con la Iglesia Católica chilena, la suma de investigaciones llevadas a cabo por el jesuita Renato Poblete (1924-2010) son de particular interés, en tanto reflejan por un lado las expectativas en torno al ciclo de transformaciones, como los factores de efectuación que operaban como condicionantes del desempeño temporal de la institución católica. Así, la contingencia era caracterizada por Poblete como una época "pluricultural, una cultura pluralista en que no existe ya un criterio único de normas y valores, sino una constante lucha entre ideologías y valores opuestos: el cristianismo, el laicismo, el comunismo". Esta situación obligaba a modificar prácticas y actitudes tradicionales en el catolicismo no solo chileno, sino continental, en tanto "el catolicismo latinoamericano ha acentuado quizás demasiado unilateralmente la parte escatológica y la salvación personal, estableciendo una dicotomía entre lo temporal y lo espiritual”, que provocaba que la Iglesia se encontrase "en una situación difícil para adaptarse a los problemas del desarrollo social y económico". Desde una posición además minoritaria, el catolicismo debía adoptar como política "la infiltración de las estructuras profanas más que la creación o expansión de las propias estructuras", jugando en ello un papel central el fortalecimiento de la acción social, la "difusión de nuestra doctrina ante las grandes masas" y la política de entrega de tierras ejemplificada por el obispado de Talca, que representaba "el símbolo más alentador de la adaptación de la Iglesia a este cambio irreversible hacia una mejor vida del campesinado"19.

Será justamente en la publicación más amplia de sus resultados de investigación que Renato Poblete expresará con mayor detalle su definición del mundo secularizado, al momento de mirar hacia el pasado y resaltar más que lo existente, lo que ya no estaba, lo estrictamente histó-

18 "Obispado de Talca entregó tierras: la Iglesia termina con el Inquilinaje", en La Voz (1 de julio 1962) 8-9.

19 R. Poblete, "La situación religiosa en Chile”, en Teología y Vida 3/4 (cuarto trimestre 1962) 229-235. 
rico: ante la evidencia de que en Chile había más de 12 mil habitantes por parroquia, el jesuita reflexionaba:

"estos números se deben interpretar en un contexto totalmente diferente del que teníamos 50 años atrás. La parroquia era la estructura básica de la Iglesia, y antiguamente, pese a su tamaño, era el centro de gran parte de las actividades del cristiano. Su planta física estaba en el centro de los pueblos o de las ciudades. En esa sociedad monocultural no había gran problema de transmisión de normas y valores, esto es, de la cultura cristiana. Las agencias de socialización, o mejor, de cristianización, no eran antagónicas. Había otras instituciones intermedias que cooperaban al proceso de cristianización: escuelas, gremios, cofradías, y sobre todo, la familia. La presión social era más rígida, y ella con sus aprobaciones y sanciones ayudaba a que los valores recibidos de los antepasados no cambiaran tan rápidamente. En una palabra, el valor de la tradición era grande y la parroquia podía desarrollar su influencia benéfica aun en medio de varios miles de habitantes.

Hoy vivimos en una cultura pluralista; una serie de subculturas son las que dan sus respectivas normas y valores que, a veces, están en contradicción con los valores básicos del cristianismo. Ya no existe monopolio de ideas cristianas. El cambio social acelerado por las comunicaciones humanas hace que los valores tradicionales no puedan ser trasmitidos con la misma facilidad y velocidad. Hay una presentación de otros valores que compiten con los valores cristianos. La autoridad que facilita la transmisión de normas ya no tiene el valor de antes. La mera presentación de verdades desde un púlpito ya no basta. Faltando el apoyo de grupos intermedios que ayuden en el proceso de cristianización, la labor parroquial es hoy totalmente distinta a la de hace 40 o 50 años" 20 .

De esa forma, y en un tono de objetivada certeza, la investigación del jesuita plasmaba en una larga enumeración de cifras la efectiva situación de cambio histórico, que debía de ser afrontada por parte de la Iglesia Católica con las herramientas de la socialización y la parroquia, de la acción social y la divulgación. Es decir, con la estrategia de una minoría, grande e influyente, pero una entre otras. Sin embargo, y como interesa destacar aquí, lo que debe llamar nuestra atención es el peso de la impresión del cambio, su cualidad de horizonte de reflexión y acción por parte de los católicos activos. Así, y en una orientación sin duda más op-

20 R. Poblete, La Iglesia en Chile (FERES, Friburgo-OCSHA, Madrid, 1962) 70-71. 
timista pero no menos informada, la reseña que la revista Teología y Vida realizó en torno a la Carta Pastoral "El deber social y político en la hora presente" sintetizaba el contexto y pertinencia de su aparición bajo una bella fórmula del cambio histórico: "lo que era un apacible curso de agua hoy es impetuoso torbellino", en el cual "nuestro espíritu parece no acomodarse todavía en nuestros tiempos y cae fácilmente en el error" ${ }^{21}$, aun cuando la misma Pastoral era saludada como un paso significativo en la adecuación de la opinión eclesiástica y las transformaciones del mundo.

La centralidad de esta percepción del cambio histórico por parte de los agentes del pensamiento católico quedó en más establecida al momento en que desde los noveles centros de investigación sociológica de inspiración cristiana se elaboró un acabado análisis -encabezado por el sacerdote jesuita y sociólogo norteamericano Joseph H. Fichter (19081994) - referido a las percepciones en torno al cambio social en Chile, que fue publicado por la editorial de la Universidad Católica en 1962, y que se articuló bajo la pregunta central de "quienes están dispuestos y quienes no están dispuestos al cambio"22. Las encuestas destinadas a informar la investigación fueron dirigidas exclusivamente a un grupo de poco más de mil "católicos nucleares", es decir, intensamente comprometidos con las instituciones de la Iglesia Católica. De ellos, 328 eran sacerdotes, 488 laicos varones y 188 mujeres católicas ${ }^{23}$. Como grupo, al ser preguntados por la naturaleza del cambio histórico en Chile, cerca del $60 \%$ se manifestó descontento con la lenta velocidad de este, opinando lo contrario solo una séptima parte del total de la muestra, en términos de que este cambio operaría de forma muy acelerada. Coherente con ello, un $62 \%$ de los encuestados preveía "algún tipo de trastorno social en el futuro cercano", muchos de ellos una revolución, ya fuese pacífica -cuatro sobre diez-, o violenta, según un quinto de los informantes $^{24}$. Con más detalle, la percepción sobre la velocidad del cambio

21 "Pastoral de pastorales", en Teología y Vida 3/4 (cuarto trimestre 1962) 256-259.

22 J. H. Fichter, Cambio social en Chile. Un estudio de actitudes (Editorial Universidad Católica, Santiago de Chile, 1962) 11. Sobre la formación de los centros de pensamiento social católico en el periodo en Chile y su relación con redes intelectuales de carácter trasnacional, ver de F. Beigel, Misión Santiago. El mundo académico jesuita y los inicios de la cooperación internacional católica, LOM, Santiago de Chile, 2011).

23 J. H. Fichter, Cambio social en Chile..., 24 y 27.

24 J. H. Fichter, Cambio social en Chile..., 30. 
histórico era indicada por un $18 \%$ de los sacerdotes como muy rápida, por un $22 \%$ como adecuada y por más del $57 \%$ como muy lenta ${ }^{25}$. De forma sintomática, el grupo de sacerdotes que percibió esta velocidad como más lenta fue mayoritariamente el de los anglosajones, que así lo calificaron en casi un 75\%, mientras que la misma opinión fue propuesta por el $55 \%$ de los clérigos provenientes de países latinos, y por el $54 \%$ de los nacionales ${ }^{26}$.

Del total de los religiosos encuestados, por su parte, cerca del $60 \%$ consideró inminente una revolución, opinando la mayoría que esta sería pacífica, y casi el 25\% que sería violenta. En el total de la muestra, quienes más se pronunciaron sobre el carácter violento de la revolución fueron las mujeres, en tanto una de cada cuatro sostuvo ese juicio, contra solo un $18 \%$ de los varones ${ }^{27}$. En términos de edad, aquellos conceptuados como jóvenes consideraban mayoritariamente (casi 70\%) que la velocidad del cambio era muy lenta, mientras que para más del $60 \%$ de los encuestados de mayor edad, esta era o adecuada, o muy rápida ${ }^{28}$. En esta afirmación, además, el autor verificaba que comparativamente eran los sacerdotes más "progresistas" que los laicos, ya sean jóvenes o de mayor edad, en tanto su tasa de "impaciencia" frente al cambio era siempre mayor ${ }^{29}$. De forma relacionada, tan solo un $8,5 \%$ de los encuestados que se ubicaban en las clases altas consideró el cambio como muy rápido, cifra que entre aquellos identificados como parte de las clases bajas alcanzó a casi un $15 \%{ }^{30}$. En términos de las percepciones de clase, el estudio del sacerdote estadounidense presentaba además inferencias de gran interés: por un lado, afirmaba que "el hecho de que la gente de clase alta tenga poca fe en las capacidades de las clases bajas, y de que no esté dispuesta a compartir las ventajas económicas con otros, son dos síntomas de la rígida estructura de clase que impide a Chile convertirse en una sociedad abierta"; por otro, que la distancia entre unas clases y otras "que nuestros informantes estiman que está aumentando, puede finalmente definir la diferencia entre el cambio social ordenado y el tras-

\footnotetext{
J. H. Fichter,, Cambio social en Chile..., 46.

J. H. Fichter, Cambio social en Chile..., 70.

J. H. Fichter, Cambio social en Chile..., 96.

J. H. Fichter, Cambio social en Chile..., 115.

J. H. Fichter, Cambio social en Chile..., 128-129.

30 J. H. Fichter, Cambio social en Chile..., 176.
} 
torno social revolucionario"31. Así, es en la estructura de clases predominante en Chile que el conjunto de los "católicos nucleares" observaron los síntomas, los problemas y las vías de resolución del cambio histórico, en tanto que la conclusión a la que el investigador arribó expresaba que:

"el cambio central que Chile necesita -la remoción de las barreras de status para el desarrollo humano- requiere que se permita a las personas de clase baja ejercer sus capacidades. Más que eso, requiere una convicción de que estas personas no privilegiadas tengan por lo menos las capacidades potenciales para contribuir en forma positiva a la sociedad, para aprovechar sus valores culturales y compartir sus responsabilidades sociales" 32 .

Esta conclusión hacía mención, entonces, al fenómeno gatillante del cambio histórico como inminencia. Puntualmente, sin embargo, la indagación que hemos reseñado concluía haciendo referencia al papel de la Iglesia Católica en estas transformaciones y su capacidad -así como de las personas que se identificaban con ella- de adaptarse a las nuevas condiciones por estas producidas. En tal sentido, Fichter no dudaba en expresar que "si la religión es la fuerza social dinámica que todos nuestros encuestados creen que es el papel que cumpla en la sociedad debe ser definido más por actitudes de los progresistas, que por las de los tradicionalistas" 33 . Poco más tarde, el mismo Fichter declaraba a una revista estadounidense que dedicaba un reportaje a la situación de la Iglesia en Latinoamérica que en Chile, los católicos de clase alta, graduados de universidades católicas,

"no tienen fe en los seres humanos, no confían en el hombre común; ellos no creen que los campesinos puedan ser exitosamente preparados en nuevas técnicas agrarias; ellos no creen que los hijos de los trabajadores puedan tener éxito como estudiantes universitarios. En otras palabras, la educación que estas universidades han dado a su graduados no contiene los más importantes valores de una sociedad cristiana y democrática que pueden fundirse en la creencia de que la capacidad y la oportunidad para aprovechar tales habilidades no

31 J. H. Fichter, Cambio social en Chile..., 180 y 192.

32 J. H. Fichter, Cambio social en Chile..., 210.

33 J. H. Fichter, Cambio social en Chile..., 225. 
son privilegio de una clase, una raza o de un tipo determinado de familia" ${ }^{44}$.

El mismo tipo de contenido fue explícitamente remarcado por el encargado de la reseña del texto para la revista de la Facultad de Teología de la Pontificia Universidad Católica de Chile, quien destacaba los dos puntos antes anotados: por un lado, el hecho de que se observaban diferencias muy acentuadas entre aquellos que manifestaban "la fe y la confianza en las masas para intervenir válidamente en el cambio", versus quienes mantenían "una falta de confianza en ellas", lo que era interpretado como "un índice de la resistencia de las clases altas a admitir cualquier cambio que afecte su propia posición económica, o que implique competencia humana de parte de la gente de clase baja”. Por otro lado, en su análisis, el comentarista subrayaba el hecho de que, a juicio de los encuestados la religión representaba "una de las principales fuerzas de la sociedad chilena”; y que para que esta situación se consolidara, el papel que jugase en relación a los cambios que se avecinaban debía "ser definido más por las actitudes progresistas, que por las de los tradicionalistas" 35 , evidenciándose la fractura política presente en la Iglesia en un contexto de aceleración de las transformaciones. Con una coherencia muy llamativa, el informe de un anónimo participante de la Misión Rural de 1963 expresaba que uno de los problemas más acuciantes del mundo campesino era el hecho de que los patrones no lograban comprender al inquilino como "un hombre adulto (responsable, libre y con iniciativa)", y menos aún que "algún día puedan ser co-patrones con ellos" 36 .

De forma singular, la percepción que de este giro histórico manifestaba el obispo de Talca Manuel Larraín es ilustrativa: advirtiendo que no pretendía "hacer un estudio sociológico", indicaba en la segunda parte de 1962 que "Chile está al borde de inminentes y profundos cambios estructurales que van a influir en nuevas formas sociales, culturales, económicas y políticas", particularmente en el plano demográfico y la migración rural-urbana, fenómeno sobre el cual la prognosis de Larraín preveía que "la década 1960-1970 va a ser fatalmente la de la explosión

34 L. Gross, "La Iglesia en América Latina”, publicado originalmente en "Look", traducción publicada en Política y Espíritu 276 (noviembre 1962) 17-24.

35 "Cambio Social en Chile", en Teología y Vida 4/1 (primer trimestre 1963) 63-64.

36 "Balance personal de un misionero de la Misión Rural", en Pastoral Popular 75 (mayo-junio 1963) 38-40. 
del mundo rural", insistiendo -al momento de reconocer que el Episcopado en su conjunto era consciente de ello, tal y como lo demostraba la Carta Pastoral dedicada al problema campesino en Chile, publicada poco antes- que "con certeza y sin temor a equivocarme, os digo que los años que se avecinan nos harán ver reformas agrarias muy hondas o bien explosiones revolucionarias de tipo cubanas". Por ello, "soñar en que vamos a permanecer iguales que antes no es solo ilusión, sino ceguera. $Y$ lo que sería más grave, ceguera culpable”. Para el obispo, el tránsito del sistema económico capitalista a otro de naturaleza distinta era el factor dominante de la condición que denunciaba, y ante esa transformación, consideraba que la Iglesia no debía hacerse solidaria con las estructuras vigentes, en tanto, y citando a Mateo 8, 22, expresaba "hay que dejar a los muertos que entierren a sus muertos" ${ }^{37}$, dejando así claro que el modelo de organización que suponía más cercano al cristianismo se encontraba en un lugar distinto.

En el mismo sentido, y dando cuenta de una visión de alcance regional, el jesuita Juan Ochagavía consideraba en la segunda parte de 1963 que la situación de la Iglesia Católica sudamericana estaba marcada por una "teología de las realidades temporales" que daba cuenta de las transformaciones estructurales ocurrentes y por ocurrir, y que la obligaba a "reconocer y respetar el valor intrínseco de lo temporal", permitiendo ello repensar "varios problemas concretos, como las relaciones entre la Iglesia y el Estado, la misión de las universidades católicas, la existencia de sindicatos confesionales, etc.". En ese escenario, a juicio de Ochagavía "será tarea de la próxima generación encontrar un verdadero equilibrio entre lo institucional y lo carismático en la Iglesia" ${ }^{38}$. Pues bien, un primer acercamiento a las actitudes que ante ese tipo de desafío el mundo católico asumió es el paso siguiente a desarrollar.

\section{EL CAMBIO AL INTERIOR DE LA IGLESIA CATÓLICA CHILENA}

De forma en gran medida coherente, en instancias en que la Iglesia Católica reflexionaba sobre sí misma y la necesidad y naturaleza de las transformaciones que el "mundo" le exigía, el concepto de revolución

37 M. Larraín, "Notas para una Pastoral de emergencia", en Pastoral Popular 70-71 (julio/agosto-septiembre/octubre 1962) 26-28.

38 J. Ochagavía, "La Iglesia en la realidad actual", en Teología y Vida 4/3 (tercer trimestre 1963) 179-187. 
-como significación del cambio histórico radical- fue utilizado de forma frecuente. Así, ante la inminencia del Concilio Vaticano II el jesuita Ricardo Lombardi (1908-1979) saludaba la renovación de cada componente eclesial: quienes se entregaban a la vida religiosa y quienes debían experimentar un "empapamiento vital en la esencia cristiana" -los laicos- debían promover "la revolución cristiana universal que se espera como improrrogable" 39 . De manera muy informada, por otro lado, la investigación más arriba citada de Joseph Fichter en torno a las percepciones sobre el cambio social en el catolicismo chileno arrojaba también luces sobre la autocomprensión de la Iglesia institucional en medio de un proceso de transformaciones. Partiendo de la base del reconocimiento por la gran mayoría de los encuestado de la inminencia del cambio histórico, advertido además con características revolucionarias, el autor declaraba en las primeras páginas de su texto el hecho de que la Iglesia Católica chilena debía considerarse como la más progresista del continente, tanto por sus declaraciones como por sus acciones, estas últimas en el plano de la formación de sacerdotes en los seminarios reformados y en la ampliación de la acción social del laicado ${ }^{40}$. Pues bien, en lo que competía a la Iglesia como unidad, Fichter declaraba que había sectores a su interior que reconocían esta situación y se hallaban comprometidos con la acción social como primera tarea laical o clerical. Sin embargo, este tipo de opinión si bien era mayoritario, lo era solo por una diferencia porcentual pequeña (60/40). En vista de ello, en la conclusión el jesuita indicaba:

"el punto capital de este análisis acerca de la religión y de la gente de espíritu religioso, no reside en la posibilidad de reformar una costumbre o una función particular, sino en saber si la institución religiosa como un todo está preparada para realizar las adaptaciones requeridas por el avance de la sociedad chilena" ${ }^{41}$.

Un diagnóstico y admonición al cambio profundo en el funcionamiento de la Iglesia Católica chilena fue elaborado por las mismas fechas por el Obispo de Talca, Manuel Larraín, que en primer lugar advertía que, a inicios de la década de 1960, se estaba frente "al fin de un régimen económico y social que no tenemos por qué identificarlo con el

\footnotetext{
39 R. Lombardi, "La Revolución de los cristianos", en $\operatorname{La} V o z$ (16 de septiembre 1962) 10.

40 J. H. Fichter, Cambio social en Chile..., 16.

41 J. H. Fichter, Cambio social en Chile..., 225.
} 
ideal cristiano ni hacernos solidarios de él". Esta situación derivaba en la necesaria atención que la Iglesia Católica debía dar a los sectores populares -siempre a su juicio amenazados por el avance del marxismo-, y en lo que aquí interesa destacar, en una serie de ajustes y desafíos que la misma institución internamente debía afrontar, y que para el caso de América Latina, pasaba por una re-evangelización, en tanto "en nuestras diócesis hay zonas humanas y geográficas prácticamente no evangelizadas". Para una tarea como esa, la escasez de sacerdotes era -aun tomando en cuenta la presencia significativa de clero extranjero en el país- un factor imposible de no considerar, en tanto derivaba ya no solo en el avance de la descristianización (asociada a la secularización), sino que a la no cristianización, "o sea, la ausencia práctica de la Iglesia de grandes zonas humanas o geográficas de nuestra diócesis". Por ello, Larraín pondrá un primer acento en la necesidad de unidad de la Iglesia, convocada bajo un plan pastoral común, en tanto

"la realidad social muestra la íntima relación de una parroquia con otra, de una región con otra, del campo con la ciudad, de la Acción Católica especializada y de la parroquial, del clero secular y de los religiosos, del laicado y del sacerdocio, de los colegios y de la acción diocesana. Ninguna obra es un fin en sí misma. Aislarse no es solamente hacerse infructuoso, es sustraerse a la realidad social y traicionar el plan de la Iglesia" ${ }^{42}$.

De esa forma, y reuniendo "lucidez y unidad" en la acción eclesial, el obispo de Talca se refería a la implementación de un "plan de emergencia”, ante el diagnóstico que desde el Vaticano se hacía sentir, en tanto la Curia solicitaba al episcopado del continente "la urgencia improrrogable de actuar un plan casi de emergencia para tutelas y defender el patrimonio sagrado cristiano de los países latinoamericanos amenazados hoy gravemente". Al profundizar en la caracterización urgente del plan propuesto, Larraín subrayaba que este debía ser "a corto plazo, sin descuidar otro a mayor plazo. De emergencia, ágil y ejecutivo; de emergencia, que tome medidas que no cabrían en una situación normal, pero que sí deben caber en una como esta". Del mismo modo, dicho plan debía tomar "los puntos vitales de los problemas", concentrándose en aquellos conceptuados como más graves. Al comentar la implementación efectiva del plan, sin embargo, el Obispo recalcaba que "nada nuevo" debía de

42 M. Larraín, "Notas para una Pastoral de emergencia...", 26-28. 
inventarse, que se trataba en lo esencial de "vitalizar al máximo lo que existe", "coordinar la acción para que todas las actividades en vez de dispersarse se sumen, establecer una jerarquía de valores en las acciones". En el fondo, esta jerarquización pasaba por "consagrar especial atención a aquellos sectores que tienen mayor importancia en la vida social y a ellos dedicar preferentemente tiempo, hombres y energía".

Así, el trabajo eclesiástico debía privilegiar más a los hombres que a las mujeres, a los adultos que a los niños, más a los trabajadores activos que a los jubilados. Del mismo modo fortalecer el trabajo en las escuelas católicas, tanto con alumnos y alumnas, como con el profesorado primario y secundario; y en las parroquias, profundizando el trabajo con laicos. En otra línea, los recursos disponibles en las parroquias debían ser utilizados de modo eficiente, privilegiando antes que accesorios exteriores, el "formar catequistas, distribuir Evangelios o Catecismos, suscribirse a $L a V o z$, ayudar a la formación de Seminaristas, etc.”. Pues bien, esta "pastoral intensiva”, que focalizaba esfuerzos, debía ir acompañada de una "pastoral extensiva", es decir, "utilizar los medios actuales de difusión y propaganda que llegan a toda la masa", como la prensa, la radio -a través por ejemplo del programa radial emitido por el Instituto de Educación Rural-y el cine.

El aspecto "social" más relevante de este plan de acción pastoral enunciado por Larraín -y que aquí interpretamos en la lógica de un autodiagnóstico renovador de la Iglesia Católica chilena ante las consecuencias del cambio histórico- estará dado por la declarada centralidad que el trabajo con trabajadores adultos debía tener, así como su proyección a las clases medias. En primer lugar, y a través del Movimiento Obrero de la Acción Católica (MOAC), "orientar a los católicos hacia las Cooperativas y los Sindicatos", en segundo, y en lo fundamental a través de Centros de Padres, el Movimiento Familiar Cristiano y la misma Acción Católica, buscar "los puntos de contacto con la clase media". En el caso del mundo rural, la acción eclesiástica debía salir de la parroquia como lugar físico, y expandirse hacia "el caserío, el fundo, la quebrada, la rinconada, es decir, el grupo humano, la comunidad básica”. Junto con ello, la necesidad de "ir independizando los lugares de culto y de misiones de la casa y tutela patronal", con el fin de "mostrar que el servicio religioso es de la comunidad, que la Iglesia no llega a esa comunidad por medio de nadie". En el fondo, se debía "con caridad y prudencia, pero con firme- 
za, desvincular la práctica religiosa de la acción patronal". Camino para ello sería de acuerdo a Larraín quitar "todo aquello que puede alejar al pueblo de la Iglesia, y que marca una odiosa distinción, como mantener diferentes clases en funerales, matrimonios y bautizos", es decir, rechazar el lujo ostentoso y homologar los sacramentos independientemente de la extracción social de quienes participasen en su celebración.

Todas estas tareas tenían que ejecutarse a partir de la retomada idea de evangelización; de la formación sistemática de laicos, bajo el concepto de "apostolado laico", más activo y con facultades de colaboración directa con el clero; y de la Acción Social, inspirada en la Doctrina Social de la Iglesia, así como en los documentos episcopales locales. Junto a ello, un factor clave para Larraín era lo que denominó "la colonización de los fundos", en alusión a la entrega de parte de las propiedades agrícolas de la Iglesia a manos de sus campesinos, como el mismo Obispado de Talca había hecho ya. En tal sentido, el sacerdote veía en ello una oportunidad de reunir y administrar recursos provenientes de las propias comunidades, por medio de la transferencia del costo del culto a los cristianos, que representaba a su juicio un conjunto de ventajas:

"deja a la Iglesia más libre, prevenimos el evento no difícil que un día cercano la Iglesia pueda ser desposeída de los bienes que hoy la ayudan a vivir. No la hace una Iglesia que tenga que mirar al presupuesto y con ello a los políticos, y sobre todo ayuda a lo más urgente entre nosotros, dar a nuestros católicos el sentido de pertenencia a la Iglesia" ${ }^{43}$.

De ese modo, en la visión de Larraín -estrictamente conectada tanto con la orientación proveniente desde Roma como con los debates y posiciones al interior del Episcopado chileno- el objetivo de renovación de la Iglesia Católica pasaba en lo fundamental por el cambio de prácticas al interior de la misma y las estrategias de relación con las comunidades católicas. En tal sentido, es de enorme interés la jerarquización de objetivos de cristianización -hombres trabajadores y con capacidad de participación e injerencia político-social-, así como los intentos de desvinculación con respecto a las clases patronales y un acercamiento sistemático a las clases medias y el mundo popular. Para cambiar, la Iglesia debía estar donde los fenómenos se transformaban. Ejemplo de la ralentización o dificultad de este cambio de actitud por parte de la institución puede

43 M. Larraín, "Notas para una Pastoral de emergencia...", 26-28. 
ser representado en la crítica que un lector de Mensaje -que se identificaba como dirigente sindical- hacía a la construcción del nuevo colegio jesuita en uno de los barrios más acomodados de la ciudad, acción que a su juicio era un "signo visible" de la Iglesia que "en nuestra opinión de cristianos, constituye un insulto a los pobres y analfabetos de Chile y a los conceptos usualmente vertidos en Mensaje". De todas formas, el lector se manifestaba confiando en que "la Iglesia está cambiando y va a cambiar mucho más después del Concilio" ${ }^{44}$.

En esta misma dirección se orientaba la reflexión publicada en $\mathrm{La} V \mathrm{Vz}$ por el sacerdote Osvaldo Salgado, quien a partir de los debates generados por las interpretaciones surgidas en torno al carácter anticomunista de la Pastoral referida al papel político y social de los católicos publicada en septiembre de 1962, definía a la Iglesia Católica como un "cuerpo vivo" que necesariamente debía cambiar, un cuerpo que "crece, evoluciona, se adapta", pero a partir de un núcleo o "alma" estable, un conjunto de principios doctrinales inmutables, dentro de los cuales sin lugar a dudas habitaba el anticomunismo. Pero, y es esto lo que nos interesa destacar aquí, este fondo doctrinal no debía - a juicio del sacerdote- ocultar el hecho de que "la Iglesia está formada por una variedad de miembros que se integran en su cuerpo y cambian según las circunstancias". Si ello no fuera así "seríamos lo que algunos adversarios pretenden que somos: un cuerpo momificado". Lo que cambiaba y debía cambiar en la Iglesia Católica eran los "métodos y criterios" para que "una Verdad que es inmutable" pudiese ser "accesible a los hombres de hoy". Por ello, la definición de colaboración u oposición al comunismo era accesoria cuando el objetivo del momento era "la aplicación de remedios mediante una acción constructiva" a los males que la Carta Pastoral había denunciado. Y eso significaba remover a la misma Iglesia, que no debía ser la que se contentase

"con predicar verdades y aconsejar paciencia y mansedumbre, sino la que da alimento al que tiene hambre y da ropa al que viste andrajos, es salario justo y cultura para todos. Muchas veces nos quedamos con lo divino de la Iglesia y pretendemos cumplir nuestra labor únicamente con lo espiritual. Postergamos lo humano de la Iglesia y desdeñamos la acción social. El samaritano fue buen samaritano porque asistió al herido y no se acercó para aconsejarle conformidad y leerle un pasaje de la Biblia.

44 “Renovar el rostro de la Iglesia”, en Mensaje 118 (mayo 1963) 136 y 202. 
Basta ya de suspicacias políticas, enfermedad de los chilenos; realizar la justicia social de acuerdo a métodos exigidos por los tiempos que vivimos no significa identificarse con corrientes políticas, sino vivir la Iglesia viva. Aferrarse a lo tradicional por miedo a ser heterodoxos o por romanticismo es rendir culto a un ídolo y no al Dios viviente" ${ }^{\$ 5}$.

Con expresiones de ese tipo, se seguía de cerca la convicción profunda que el obispo Manuel Larraín expusiese en el Concilio Vaticano II: "la Iglesia debe amar la renovación y la adaptación como una característica inherente al pueblo peregrino" 46 . En este contexto es interesante dar cuenta de la reflexión que -en los marcos de una larga e informada descripción y conceptualización de las reformas estructurales demandadas por América Latina publicada por la revista Mensaje a fines de 1963- el sacerdote jesuita Mario Zañartu ( $;$-1998) elaboró tratando de responder si el catolicismo operaba como un factor de refuerzo o ralentización del cambio. De forma esperable, el autor señalaba que en el catolicismo latinoamericano -y por ello en el chileno, debemos suponer-convivían ambos tipos de actitudes. En relación a los elementos que hacían del catolicismo un fenómeno reacio a las transformaciones, enumeraba: la creencia en que el orden social y sus estructuras era reflejo de la voluntad divina; la centralidad que en las personas religiosas tomaba la preocupación por la salvación, y por ello se daba una suerte de desconexión con las realidades materiales contingentes; "la resignación ante la miseria y escasez propia y ajena, por considerarlas consecuencias necesarias del pecado original"; una suerte de fatalismo ante la posibilidad real de modificar las cosas; la preeminencia de la caridad localizada y organizada en función de lazos personales; y el rechazo general que ciertas versiones de la espiritualidad y el "humanismo cristiano" suponían con respecto a las problemáticas contingentes.

Por el contrario, a juicio del mismo sacerdote -y además economistasí existían factores del catolicismo continental que podrían operar como refuerzo de las transformaciones. Entre ellos mencionaba, de manera ge-

45 O. Salgado, "El cuerpo de la Iglesia", en $\operatorname{La} \operatorname{Voz}(6$ de enero 1963) 3. A juicio de un laico de largo compromiso católico, en esas mismas fechas "la Jerarquía misma de la Iglesia y el clero parecen cambiar de fisonomía, en el lapso de una sola generación", J. Lagarrigue A., "Pluralismo político chileno", en Teología y Vida 4/4 (cuarto trimestre 1963) 245-249.

46 M. Larraín, "La función profética del Pueblo de Dios", ponencia dictada en el Concilio Vaticano II el 23 de octubre de 1963, en Escritos Completos, vol. I..., 89-91. 
neral, "una actitud favorable al cambio, puesto que la moral cristiana es una moral de respuestas concretas a problemas concretos"; "una preocupación por la vida presente, en la cual se juega la futura"; la persecución de la perfección, aún reconociendo la resignación ante lo inevitable; "el convencimiento de que poner las cosas en manos de Dios no implica una renuncia a la responsabilidad propia"; la convicción de que las buenas intenciones con el prójimo se efectúan en la acción eficaz; el amor al prójimo como proyección de la caridad y antídoto del nepotismo y la corrupción; un respeto basal a la persona humana, y por ello, a todos los niveles y categorías de ciudadanos. Tras la enumeración, Zañartu se define: a su juicio "el número y la importancia de las tomas de posición desarrollistas van en aumento y que las anti-desarrollistas se encuentran en retirada", ejemplo de lo cual sería la Carta Pastoral publicada por los obispos chilenos en septiembre de 1962. Sus conclusiones, a la vez, son muy explícitas en lo que aquí interesa destacar:

"El pasaje de las concepciones espirituales corrientes en la masa católica latinoamericana a esta espiritualidad del desarrollo, equivaldría a una verdadera mutación de actitud religiosa. Esto implica la consagración de un nuevo tipo de santidad, que nos propone como cristiano modelo a aquel que emplea todo su dinamismo en el servicio del prójimo a través de su dedicación a las reformas revolucionarias. Estamos aún lejos de haber llegado a ese grado de desarrollo religioso. Sin embargo, su advenimiento es urgente si se quiere que la revolución latinoamericana sea cristiana. Necesitamos, por tanto, también en lo religioso, un cambio rápido y profundo: una revolución” ${ }^{37}$.

Una percepción algo más optimista parecía sostener el Cardenal Raúl Silva Henríquez (1907-1999), en tanto a su juicio la Iglesia Católica ya no debía ser tratada como "enemiga de las reformas sociales", pues "estaba abocada a promover las reformas necesarias", lo cual significaba que en la situación contingente era indispensable $-\mathrm{y}$ se lo decía a un auditorio lleno de estudiantes universitarios- "cambiar nuestras estructuras, cambiar las estructuras que hemos recibido, que hemos recibido sin culpa" ${ }^{48}$. Como horizonte de orientación de este tipo de transformaciones, por las mismas fechas el obispo de Temuco, Bernardino Piñera, publicaba un detallado artículo en Teología y Vida, dedicado a explicitar los contenidos del nuevo Plan Pastoral, que tenía su foco en la acción

47 M. ZaÑARTu, "Religión y desarrollo", en Mensaje 123 (octubre 1963) 645-651.

48 "La clase del Cardenal en Valparaíso", en La Voz (19 de abril 1964) 12-13. 
social y la revitalización de la intervención práctica de los militantes cristianos. Así, partiendo del diagnóstico de que la Iglesia se esforzaba por incidir en muchos aspectos al mismo tiempo, se reconocía la necesidad de formular "objetivos pastorales", así como un "plan de conjunto" que permitiese la preparación adecuada de la acción y el control suficiente de sus resultados, en tanto la influencia social tradicional del catolicismo se veía contestada por la triple presencia del laicismo, el pentecostalismo y el marxismo, dando cuerpo así al hecho de que en Chile existía un "verdadero pluralismo ideológico, que habría reemplazado poco a poco la unanimidad católica que nos legó la Colonia”.

Esta situación motivaba a la institución eclesiástica a actuar "activamente para la ampliación" de la influencia católica, por medio de una serie de mecanismos ligados tanto al papel de la Iglesia como tal, como al de los miembros más activos de su comunidad. Así, se buscará fortalecer el rol laical, reiterando el refuerzo del contacto con sectores sociales de mayor influencia, privilegiando la actividad católica "por razones obvias, a los hombres sobre las mujeres, a los adultos sobre los niños, a la familia sobre el individuo, al sector obrero y universitario sobre los otros". De esa forma, este "pluralismo ideológico" impactaba en el común de los católicos, sumándose al hecho de que "la gran masa de los chilenos no participa activamente en la vida de la comunidad eclesial ni tienen un contacto prolongado y eficaz con algún militante del apostolado ambiental". Sin embargo -a juicio del obispo-, la mayoría de los fieles parecían conservar "un fondo cristiano difícil de avaluar cuantitativamente", que se presentaba con "desigual calidad, recubierto por diversos aportes ideológicos, alterado por fallas morales, sepultado tal vez por la indiferencia o por la premura del diario vivir, pero sin embargo muy real". Este "fondo cristiano" poseía en su opinión "una extraordinaria vitalidad", y con él en mente la Iglesia Católica debía llegar con "solicitud apostólica", presentando una imagen de sí misma "que no despierte en ellos reacciones ingratas, que no avive ninguno de los mil prejuicios que en ellos existen", y por eso "hablarles el lenguaje que ellos entienden, que no es el de la Iglesia, sino el de todo el mundo", particularmente a través de "los medios de comunicación social que la técnica ha puesto a nuestra disposición, en especial la prensa y sobre todo la radio" ${ }^{49}$. Así, en

49 B. Piñera, "Los fundamentos del Plan Pastoral del Episcopado Chileno", en Teología y Vida 5/1 (primer trimestre 1964) 5-14. 
la práctica, desde la cumbre de la Jerarquía se asumían la serie de cambios que obligaba a cambiar a la misma Iglesia Católica, y que debían de ser asumidos como condicionantes de la acción eclesial: la nueva actitud de los fieles, la situación de pluralismo ideológico y los nuevos medios de comunicación.

Como un relato que de forma sintética y ligada con la práctica pastoral concreta es capaz de dar cuenta de todo lo anterior, al reflexionar sobre los desafíos y dificultades del trabajo en el mundo campesino, el presbítero y asesor diocesano de Rancagua Orozimbo Fuenzalida (19262013) a mediados de 1964 recogía la máxima paulina de que "ya es hora de levantarnos del sueño que padecemos", lo cual implicaba que la Iglesia Católica como unidad, y en particular cada sacerdote

"tiene que bautizar este mundo que crece explosivamente; pero no sabe o no tiene audacia para hacerlo; se da cuenta que su campo de influencia no llega sino a unos cuantos, y que no son los mejores y que la gran masa se margina de su parroquia; se da cuenta que el pueblo no reacciona ya por principios de autoridad sino por valores de influencia que logra con éxito el comunismo, el protestantismo; entonces se crea en él la sensación de pánico y la conciencia de impotencia que lo llevan a una actitud defensiva o a una actitud de derrotismo consciente. En viendo venir al lobo abandona el rebaño" 50 .

\section{CONCLUSIONES}

A partir de lo aquí expuesto es factible adelantar una serie de interpretaciones que permitan ilustrar las opiniones en torno al cambio histórico, la secularización y su impacto al interior de la Iglesia Católica elaboradas por parte de algunos representantes del pensamiento católico en la primera parte de la década de 1960 en Chile. Así, en primer lugar es indispensable reconocer que la percepción de la inminencia, inevitabilidad y profundidad del cambio histórico - proyectado a todas las áreas de la vida social- fue un consenso al interior de la comunidad católica. Este consenso, sin embrago, no redundó necesariamente en un juicio uniforme en torno a las consecuencias de los cambios y su bondad o perjuicio para el país o la institución. De esa forma, convivieron -tal y como la investigación sociológica de los jesuitas Fichter y Poblete lo

50 O. Fuenzalida, "El párroco y la Acción Católica Rural”, en Pastoral Popular 83 (julio-agosto 1964) 24. 
demostraron- juicios contrapuestos referidos a la velocidad, alcance y deseabilidad del cambio. Sin embargo, el común de las fuentes aquí citadas se inclinaron por favorecer las actitudes católicas caracterizadas como progresistas antes que aquellas inclinadas hacia el rechazo a las transformaciones o la preservación del statu quo.

Esta convivencia de actitudes -que podríamos sintetizar bajo los conceptos de temor y esperanza frente al cambio histórico- se dio en los marcos del reconocimiento del despliegue de un proceso de secularización que afectaba al conjunto de la sociedad chilena, y que redundaba en lo fundamental en la asunción de una cultura pluralista y moderna, en la cual el alcance de la opinión eclesiástica y de la experiencia religiosa en general estaba encuadrado en la convivencia con otras expresiones de opinión y de creencia. En ese contexto, el pensamiento católico y las autoridades eclesiásticas que aquí hemos reseñado no solo no abandonaron el espacio de la esfera pública como espacio de opinión, sino que fortalecieron cada uno de sus dispositivos de incidencia social. En tal sentido, la vocación de intervención activa en los asuntos contingentes era un horizonte de realización indispensable en un periodo en el que distintas corrientes de pensamiento y acción hacían del debate público una herramienta de implementación de modelos de cambio histórico contrapuestos.

Finalmente, la configuración de los procesos antes mencionados -la comprensión del cambio histórico y la reacción activa ante dicho proceso en el campo de la opinión pública y la intervención social- derivó en que al interior de la Iglesia Católica se formulasen juicios referidos a la necesidad de transformación de las instituciones eclesiásticas, como procedimiento coherente para la participación de los católicos en su conjunto en los procesos de cambio, no en una posición de repliegue o temor ante estos, sino que de orientación y actuación concreta. Ello suponía, por supuesto, cambios en el oficio sacerdotal, en las lógicas pastorales, en las relaciones con la Acción Católica y los laicos militantes. Todo este diagnóstico de los planos de transformación requeridos por el mundo católico chileno se formuló de forma paralela a los debates en el Concilio Vaticano II, dejando en evidencia que, al parecer en este aspecto, la revolución interna no podía esperar. 
